\title{
3-D Viscous Flow Analysis of an Axial Flow Pump Impeller
}

\author{
STEVEN M. MINER*
}

Mechanical Engineering Department United States Naval Academy Annapolis, Maryland 21402

\begin{abstract}
A commercial CFD code is used to compute the flow field within the first stage impeller of a two stage axial flow pump. The code solves the 3-D Reynolds Averaged Navier Stokes equations in a rotating cylindrical coordinate system using a standard $k-\varepsilon$ turbulence model. Stage design parameters are, rotational speed $870 \mathrm{rpm}$, flow coefficient $\phi=0.12$, head coefficient $\psi=0.06$, and specific speed 2.86 (8070 US). Results from the study include relative and absolute velocities, flow angles, and static and total pressures. Comparison is made to measured data available for the same impeller at two planes, one upstream of the impeller and the other downstream. The comparisons are for circumferentially averaged results and include axial and tangential velocities, impeller exit flow angle, static pressure, and total pressure. Results of this study show that the computational results closely match the shapes and magnitudes of the measured profiles, indicating that CFD can be used to accurately predict performance.
\end{abstract}

Keywords: Pump, Axial Flow, 3-D, Viscous, Impeller

\section{INTRODUCTION}

Designers are continually being challenged to provide axial flow pumps that operate more efficiently, quietly, and reliably at lower cost. Key to building these machines is a better understanding of, and ability to predict their hydraulic and dynamic characteristics. Understanding and predicting these characteristics requires a detailed knowledge of the flow fields within the stationary and rotating passages of the pump. With the advent of more powerful computers, Computational Fluid Dynamics (CFD) is seeing more and more use in predicting the flow fields in both the stationary and rotating passages of turbomachines.
Lakshminarayana [1991] provides a review of the techniques that are currently being used, as well as, an assessment of the state of the art.

Most of the previous work in the area of axial flow machines has been for compressible flow, and was driven by the gas turbine industry. Adamczyk et al. [1989], and Furukawa et al. [1991] are typical examples. Examples of incompressible studies of axial flow machines are Yu et al. [1995], Yang [1995]. In both cases, compressible and incompressible flow, the solutions have been obtained using codes that are developed in house, using meshes that have in excess of 100,000 nodes, and are run on super computer plat-

*Corresponding author. Tel.: 410-293-6527. Fax: 410-293-2591. E-mail: miner@USNA.NAVY.MIL. 
forms. The hardware and time requirements for models of this size are not suitable for use in day to day design applications.

The present work uses FLOTRAN, a commercially available CFD code to obtain solutions for the flow field and pressure field within the impeller of an axial flow pump. The code is run on a Sun SPARCstation 20 , and the model size is approximately 20,000 nodes. Turn around time for geometry update and solution is one day, which makes the use of the code in the design process feasible. Results presented here include circumferentially averaged velocity and pressure profiles upstream and downstream of the impeller. The computational results are compared to measured data for the same geometry.

\section{CFD FORMULATION}

FLOTRAN is a finite element based code which solves the Reynolds Averaged Navier Stokes equations in primitive variable form. Turbulence is modeled using the $k-\varepsilon$ turbulence model, with the $\log$ law of the wall to simulate the boundary layers. The formulation of the code is based on the SIMPLER method of Patankar [1980]. For the impeller analysis discussed in this paper the equations governing the turbulent incompressible flow are formulated in a rotating reference frame. The continuity and momentum equations become:

$$
\begin{gathered}
\nabla \bullet(\rho \vec{U})+\frac{\partial \rho}{\partial t}=0 \\
\frac{D(\rho \vec{U})}{D t}+2 \rho \vec{\omega} \times \vec{U}+\rho \vec{\omega} \times \vec{\omega} \times \vec{r}=\rho \vec{g}-\nabla P \\
+\mu_{e} \nabla^{2} \vec{U},
\end{gathered}
$$

where $P$ is modified to account for effects due to rotation, and $\mu_{e}$ is the linear combination of the kinematic viscosity and the turbulent viscosity derived from the $k-\varepsilon$ model. These equations along with the appropriate boundary conditions are solved for the three components of velocity and the pressure. Boundary conditions used for this analysis include stationary and moving walls, specified inlet velocities, specified outlet pressure, and periodic boundaries.

\section{GEOMETRY}

Figure 1 shows a cross section view of the pump, which is described in detail by White et al. [1993]. The pump is a two stage design with contra-rotating impellers. The analysis presented in this paper is for the first stage impeller. Design parameters for the stage are rotational speed $870 \mathrm{rpm}$, flow rate 0.03 $\mathrm{m}^{3} / \mathrm{sec}$, and head rise $4.5 \mathrm{~m}$. These result in the following nondimensional parameters, flow coefficient $\phi=0.12$, head coefficient $\psi=0.06$, and specific speed 2.86 (8070 US). Figure 2 shows a perspective view of the impeller without the shroud in place. This particular impeller has the shroud attached to the blade tips, which eliminates the blade tip leakage flow. The hub radius varies from $0.064 \mathrm{~m}$ at the leading edge to $0.088 \mathrm{~m}$ at the trailing edge. The shroud radius is constant throughout at $0.15 \mathrm{~m}$. The Reynold's number based on the blade tip speed is $1.9 \times$ $10^{6}$.

Due to symmetry, only one of the blade passages needs to be analyzed. Figure 3 illustrates this blade passage with the appropriate upstream and downstream extensions. This becomes the geometry that is modeled in the rotating reference frame using FLOTRAN. At the inlet to domain the axial velocity is a constant based on the through flow for the pump. The absolute tangential velocity at the inlet is zero, which implies in the rotating frame the relative velocity is $-r \omega$, and the radial velocity is zero. The inlet to the solution domain is located approximately six chord lengths upstream of the blade leading edge. The only specification made at the outlet is that the static pressure in the absolute frame is uniform and set to zero. The code converts this absolute condition into the 


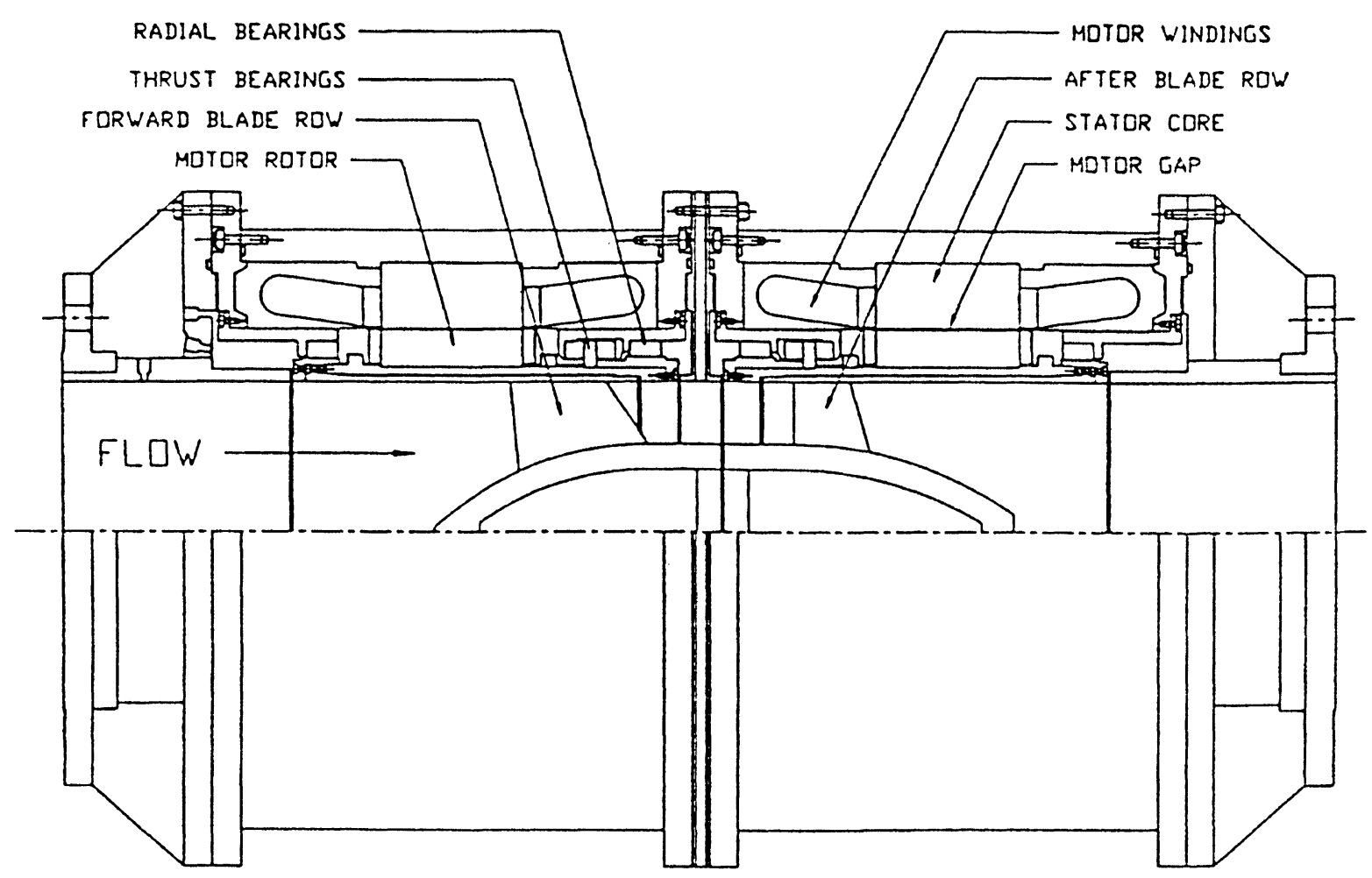

FIGURE 1 Pump cross-section.

appropriate relative pressure automatically. This condition is applied roughly eight chord lengths downstream of the blade trailing edge. Periodic boundaries are used upstream and downstream of the blade leading and trailing edges, respectively. For the rotating solid surfaces all of the velocity components are set to zero. This includes all the surfaces within the blade passage, the nose cone portion of the hub upstream of the blade leading edge, and short section of the hub, $20 \%$ of chord length, downstream of the trailing edge. The shroud surfaces upstream and downstream of the blade passage, and the reminder of the hub downstream are stationary in the absolute reference frame. In the rotating frame they are treated as moving boundaries with the axial and radial components of velocity set to zero and the tangential component set equal to $-r_{0} \omega$ for the shroud, and $-r_{i} \omega$ for the hub.
Two meshes are used in the analysis, a coarse mesh (22176 nodes), and a fine mesh (40131 nodes). The coarse mesh has 21 nodes blade to blade, 16 nodes hub to shroud, and 66 nodes inlet to outlet, of which 31 are in the blade passage. The fine mesh has 21 nodes blade to blade, 21 nodes hub to shroud, and 92 nodes inlet to outlet, of which 61 are in the blade passage. For both meshes the nodes are spaced more closely near the hub, shroud, and blade surfaces, as well as, near the leading and trailing edges. The fine mesh is used to check the solution for sensitivity to the mesh size.

The time required to generate the completed FEA model was approximately 8 hours, the solution for the initial geometry using the coarse mesh required 400 iterations and 58 hours of CPU time. Subsequent updates to the geometry and an updated solution could be obtained within 24 hours, 8 hours to modify 


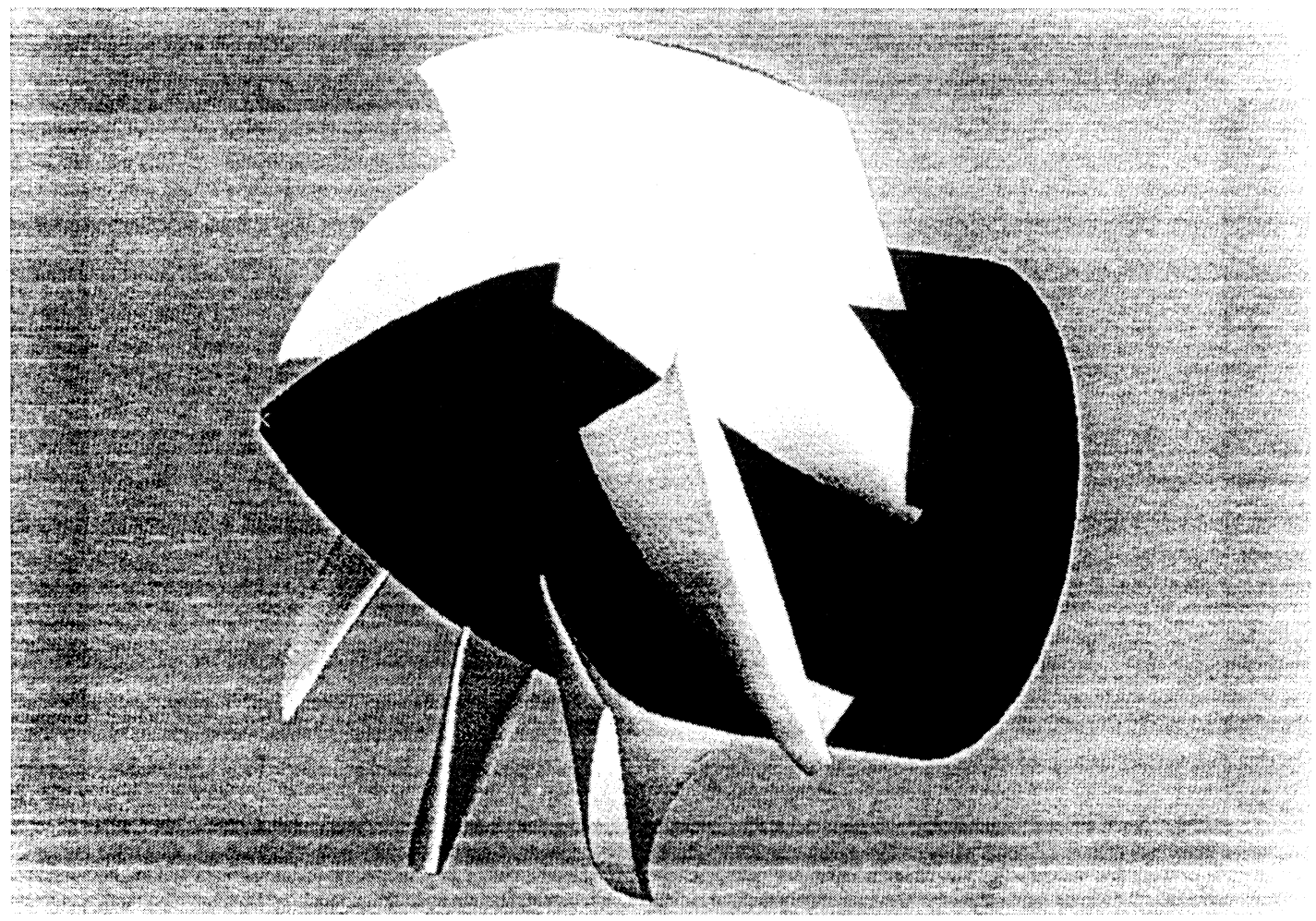

FIGURE 2 Pump impeller.

the model and 15 hours to update the solution. Updated solutions were always started from the previous converged solution. Having a one day turn around time allows CFD analysis to be used in the design process.

\section{RESULTS}

The results presented in this paper include comparisons between measured and computed data for two planes, one upstream of the impeller and one downstream. The upstream plane is three chord lengths upstream of the blade leading edge, the downstream plane is 0.2 chord lengths downstream of the blade trailing edge. Comparisons are made for the axial and tangential components of velocity, the flow angle, and the velocity magnitude at the upstream location. At the downstream location comparisons are made for the axial and tangential components of velocity, flow angle, static pressure, and total pressure. Down- stream comparisons are also shown for the 20000 node model and the 40000 node model. In addition to these comparisons, computational results just upstream of the blade leading edge are also included. For all cases the data presented are circumferentially averaged. Velocity results are absolute and nondimensionalized by the blade tip velocity $U_{t}$, pressures are nondimensionalized by $\rho \mathrm{U}_{t}^{2} / 2$, and the radius is nondimensionalized by the shroud radius $r_{0}$.

Figure 4 shows the comparisons for the upstream location. The computed axial velocity is within $10 \%$ of the measured result. The computed axial velocity profile is not as developed as the measured profile, which causes the computed profile to be flatter than the measured result. This indicates that the location of the inlet for the solution domain may need to be moved further upstream, or an alternative would be to use the fully developed turbulent profile as the inlet condition. The tangential profiles do not agree as well as the axial profiles. The difference between the measured and computed result is $2.5 \%$ of the tip speed, 


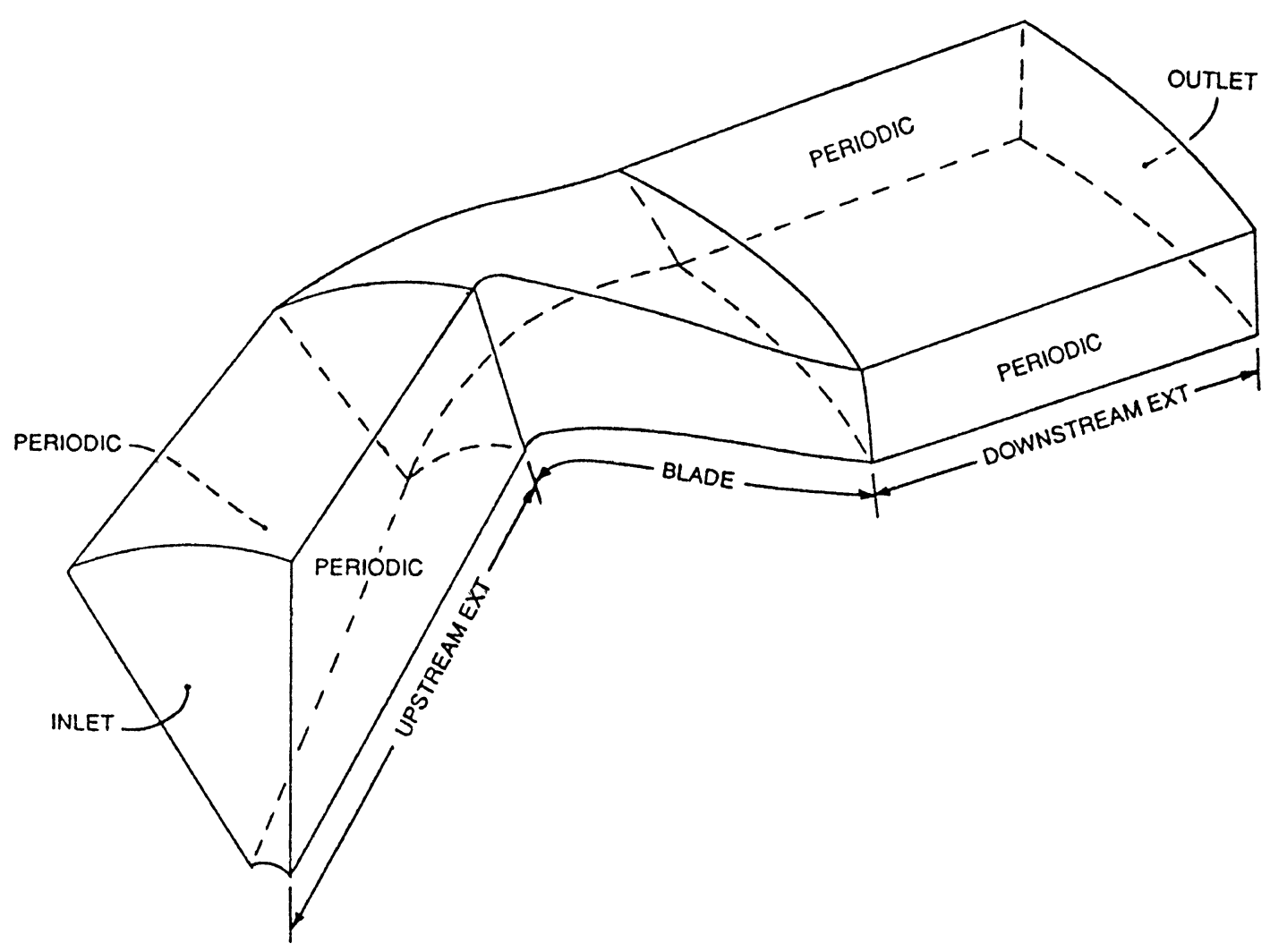

FIGURE 3 Solution domain.

with the computed result lagging the measured. Some of this difference is due to solving the equations in the rotating reference frame, where the tangential velocity at the inlet is specified as a negative value. In addition, the absolute velocity is obtained by adding the rotational speed to the velocity computed in the relative frame. Small errors in the relative velocity, on the order of $5 \%$, would account for all the difference between the computed and measured results. Despite these differences the computed and measured results both show an increase in the tangential velocity from the center line to the outer radius. This preswirl is caused by the rotation of the impeller downstream. The flow angle results show the same effects as the tangential velocity.

The velocity magnitude plot shows that the differences between the measured and computed tangential velocities are not very significant. This plot shows that the axial velocity drives the value of the magnitude.
Figure 5 shows the velocity results just upstream of the blade leading edge. The axial velocity profile shows the shift of the flow towards the outer radius caused by the presence of the nose on the hub. Also, the retarding influence of the shroud is much more pronounced. The tangential velocity shows a more pronounced preswirl, approximately 3 times the amount at the upstream location. This is caused by the shroud which rotates with the impeller.

Figure 6 gives the results of the downstream comparisons. The axial velocities agree to within $2.5 \%$ from the hub to the shroud. The axial profile shows the flow shifted back towards the hub leaving a deficit at the shroud. The computed results for the tangential velocity show more uniform turning of the flow than the measured results. At the hub and the shroud the tangential velocities show good agreement, differences midspan are as large as $14 \%$. However, the shape of the tangential velocity profile from hub to shroud is captured by the computed results. 

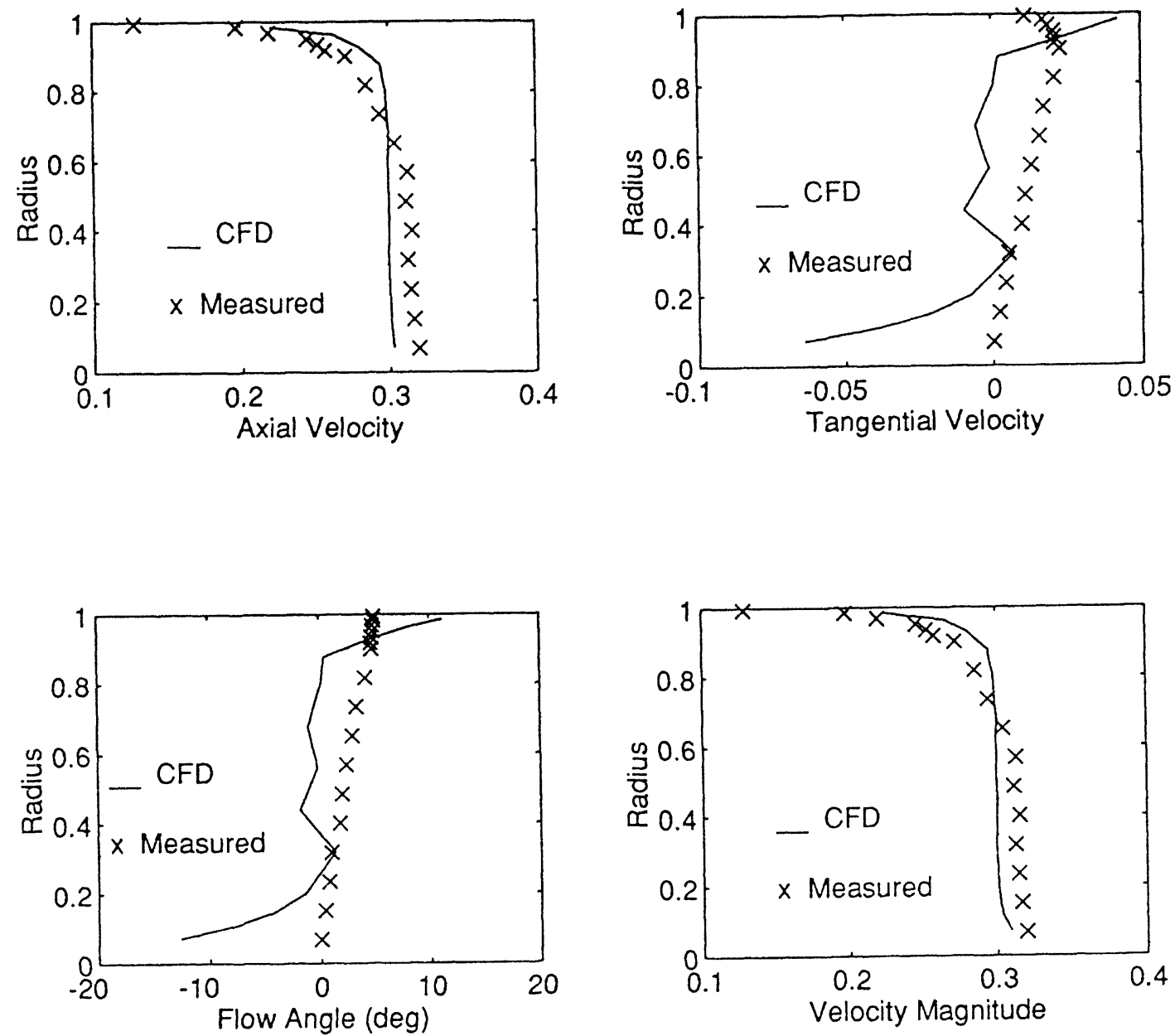

FIGURE 4 Nondimensional results, upstream location
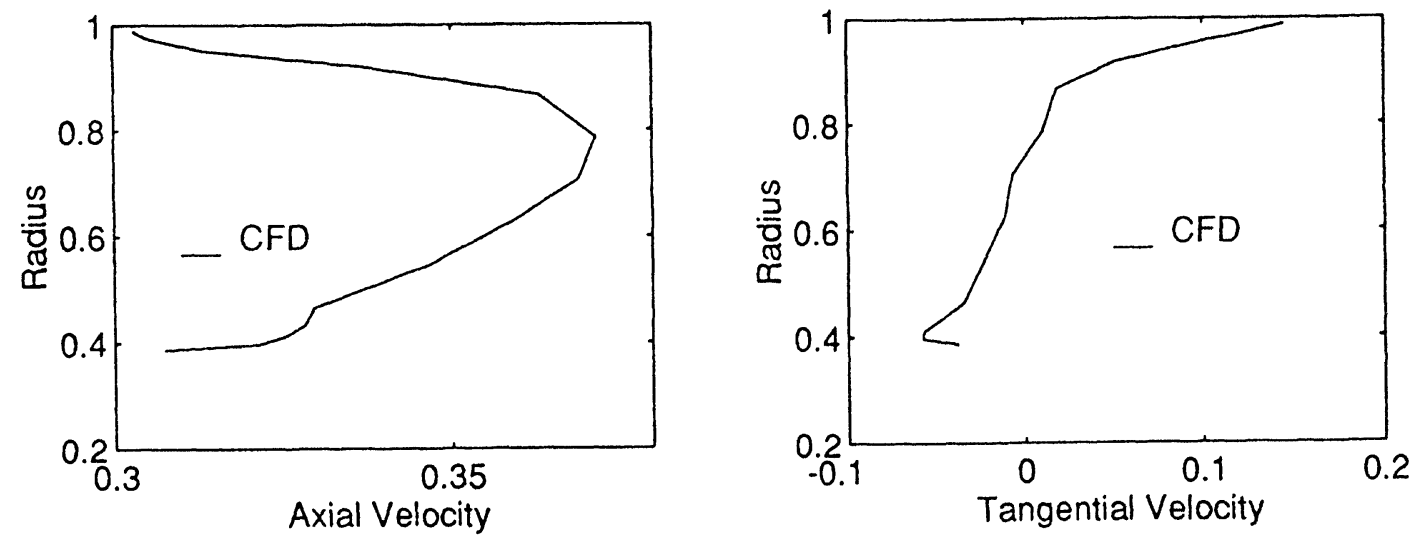

FIGURE 5 Nondimensional results, blade leading edge. 

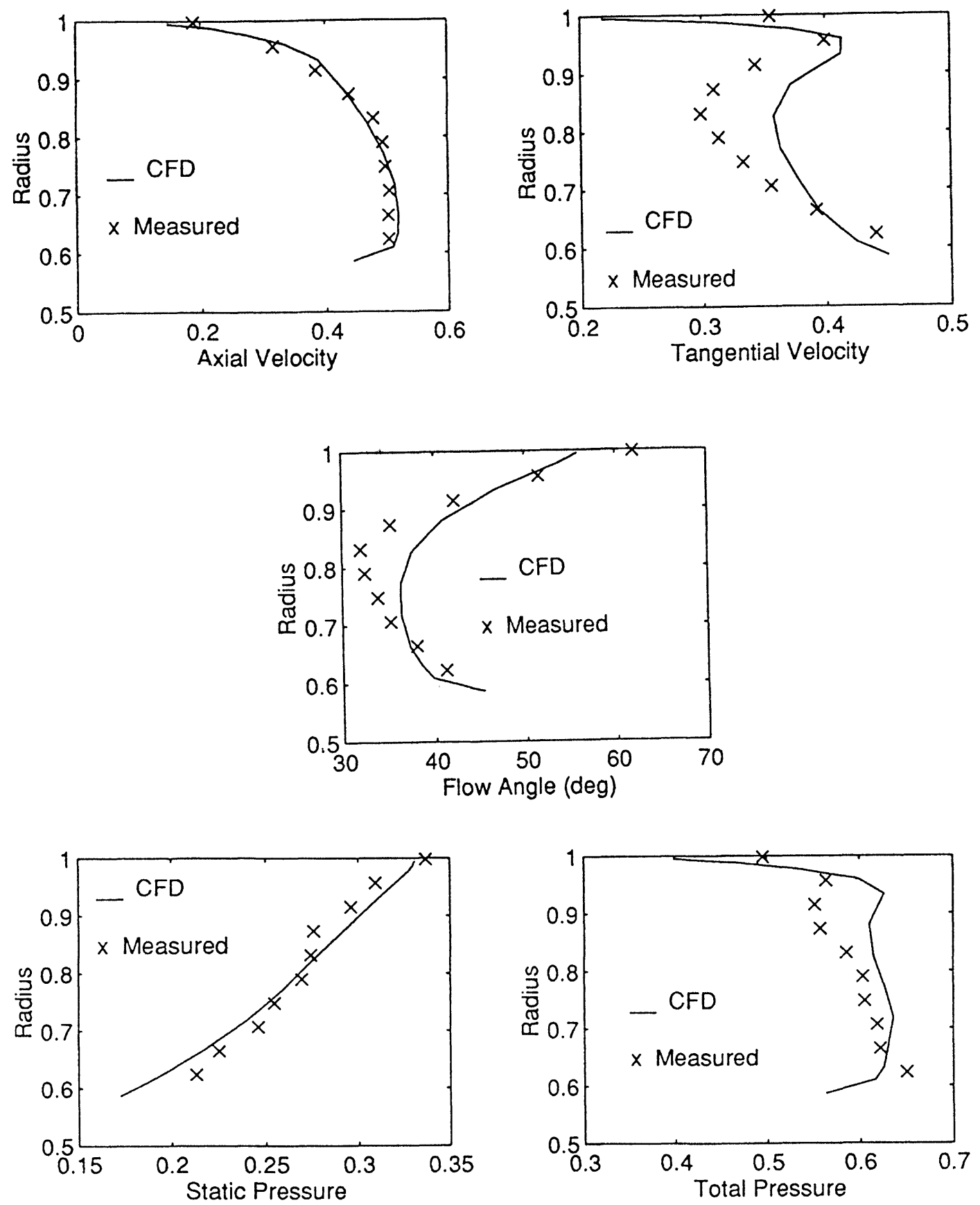

FIGURE 6 Nondimensional results, downstream location.

The flow angle results reflect the same differences that were seen in the tangential profiles. Maximum difference in flow angle between measured and computed results is $6^{\circ}$. Both the shape and the magnitude of the static pressure profile are correctly predicted. The maximum error is less than $10 \%$. The computed total pressure correctly predicts the shape of the measured profile. The differences in the magnitude are 

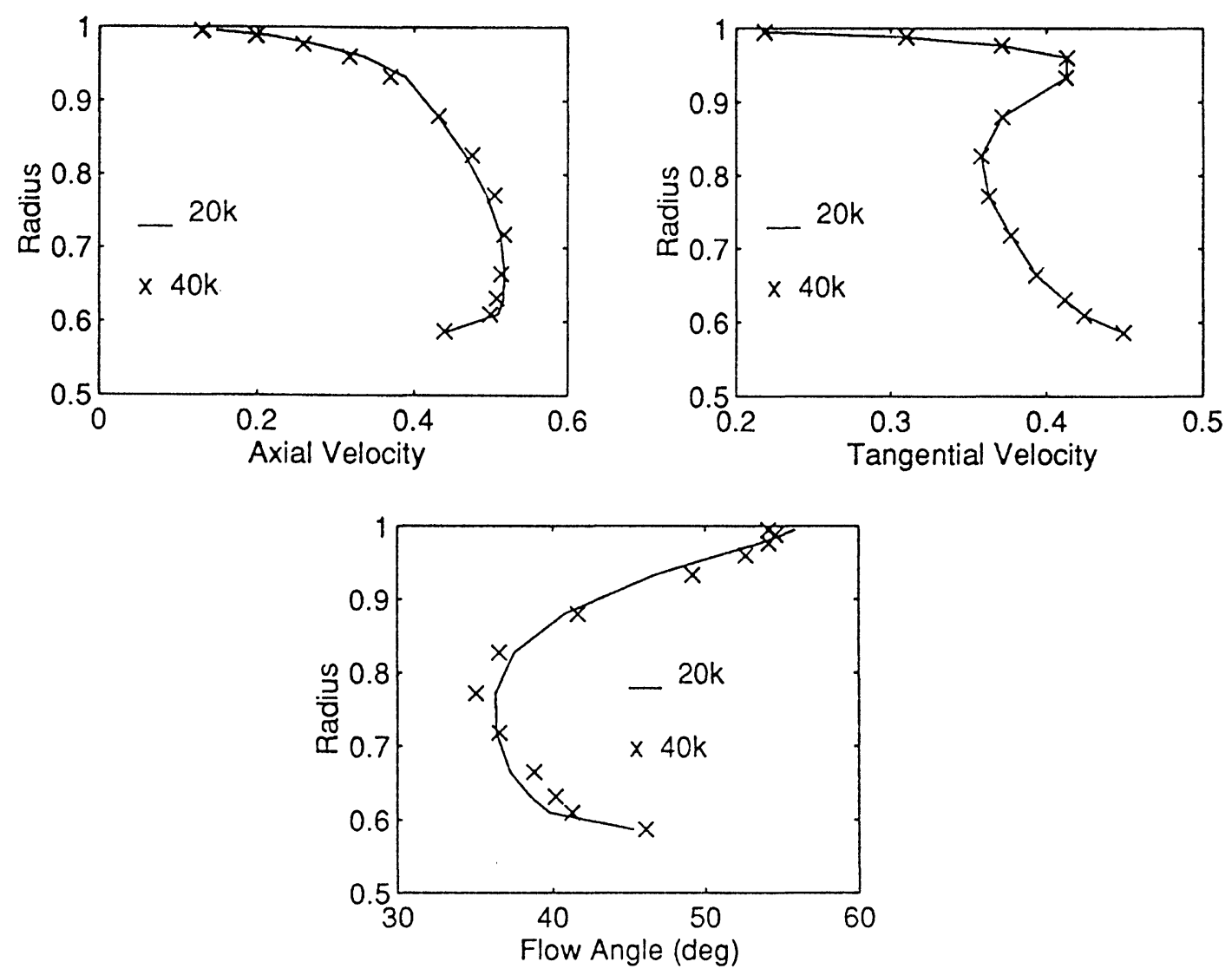

FIGURE 7 Fine and coarse mesh comparison, downstream location.

due to the differences that where seen in the tangential velocity profiles. The over-prediction seen in the tangential velocity manifests itself in the total pressure profile. Still, the maximum error in the magnitude is less than $13 \%$.

Figure 7 gives the results of the mesh comparison. None of the plots show significant differences between the coarse and fine meshes. This indicates that it might be possible to use an even coarser mesh. The advantage of using the coarsest mesh possible is that it reduces the model generation and solution times. This reduction in time makes it possible to use CFD in an iterative design process. By way of comparison, the initial solution for the coarse mesh required 400 iterations and 58 hours of CPU time, the fine mesh required 400 iterations and 111 hours of CPU time. Updates to the solutions required 15 hours and 30 hours, respectively.

\section{CONCLUSIONS}

The following conclusions are based on the results of this study.

1. Results from the CFD code showed good agreement with measured results for an axial flow pump. Both the shape and magnitude of the velocity and pressure profiles were correctly predicted. 
2. The largest errors, $15 \%$, were found in the predictions of the tangential velocity.

3. Using small models, CFD can be used effectively in the design process. Turn around times of one day are possible using a work station.

\section{Acknowledgements}

This work was supported by the Naval Surface Warfare Center, Carderock Division, Annapolis Detachment, and the Naval Academy research Council.

\section{NOMENCLATURE}

$g$ gravitational vector

$P$ modified static pressure

$\vec{r}$ radius vector

$r_{i}$ hub radius

$r_{O}$ shroud radius

$U$ velocity vector

$U_{t}$ blade tip speed

$\mu_{e}$ effective viscosity $\rho$ density

$\phi$ flow coefficient

$\psi$ head coefficient

$\vec{\omega}$ angular velocity vector

\section{References}

Lakshminarayana, B., 1991. An Assessment of Computational Fluid Dynamic Techniques in the Analysis and Design of Turbomachinery-The 1990 Freeman Scholar Lecture, Journal of Fluids Engineering, Trans. ASME, Vol. 113, No. 3.

Adamczyk, J. J., Celestina, M. L., Beach, T. A., and Barnett, M., 1989. Simulation of 3-D Viscous Flow within a Multi-Stage Turbine, ASME Paper 89-GT-152.

Furukawa, M., Yamasaki, M., and Inoue, M., 1991. A Zonal Approach for Navier-Stokes Computations of Compressible Cascade Flow Fields Using a TVD Finite Volume Method, Journal of Turbomachinery, Trans. ASME, Vol. 113, No. 4.

Yu, W. S., Lakshminarayana, B, Thompson, D. E., 1995. Computation of Three-Dimensional Viscous Flow in High Reynolds Number Pump Guide Vane, Numerical Simulations in Turbomachinery, ASME, FED-Vol. 227.

Yang, C. I., 1995. A Simulation of Viscous Incompressible Flow Through a Multiple-Blade-Row Turbomachinery with a HighResolution Upwind Finite Differencing Scheme, Numerical Simulations in Turbomachinery, ASME, FED-Vol. 227.

Patankar, S. V., 1980. Numerical Heat Transfer and Fluid Flow, Hemisphere, New York

White, J. W., Purnell, J. G., Stricker, J. G., 1993. In-Line Submersible Pump, ASME Fluids Engineering Division. 


\section{ait \\ ENERGY MATERIALS}

M A N E Y publishing

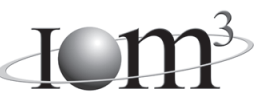

\section{Materials Science \& Engineering for Energy Systems}

Maney Publishing on behalf of the Institute of Materials, Minerals and Mining

The Institute of Materials, Minerals \& Mining

Economic and environmental factors are creating ever greater pressures for the efficient generation, transmission and use of energy. Materials developments are crucial to progress in all these areas: to innovation in design; to extending lifetime and maintenance intervals; and to successful operation in more demanding environments. Drawing together the broad community with interests in these areas, Energy Materials addresses materials needs in future energy generation, transmission, utilisation, conservation and storage. The journal covers thermal generation and gas turbines; renewable power (wind, wave, tidal, hydro, solar and geothermal); fuel cells (low and high temperature); materials issues relevant to biomass and biotechnology; nuclear power generation (fission and fusion); hydrogen generation and storage in the context of the 'hydrogen economy'; and the transmission and storage of the energy produced.

As well as publishing high-quality peer-reviewed research, Energy Materials promotes discussion of issues common to all sectors, through commissioned reviews and commentaries. The journal includes coverage of energy economics and policy, and broader social issues, since the political and legislative context influence research and investment decisions.

\section{CALL FOR PAPERS}

Contributions to the journal should be submitted online at http://ema.edmgr.com

To view the Notes for Contributors please visit: www.maney.co.uk/journals/notes/ema

Upon publication in 2006, this journal will be available via the Ingenta Connect journals service. To view free sample content online visit: www.ingentaconnect.com/content/maney

For further information please contact:

Maney Publishing UK

Tel: +44 (0)113 2497481 Fax: +44 (0)1132486983 Email: subscriptions@maney.co.uk

or

Maney Publishing North America

Tel (toll free): 8662975154 Fax: 6173546875 Email: maney@maneyusa.com

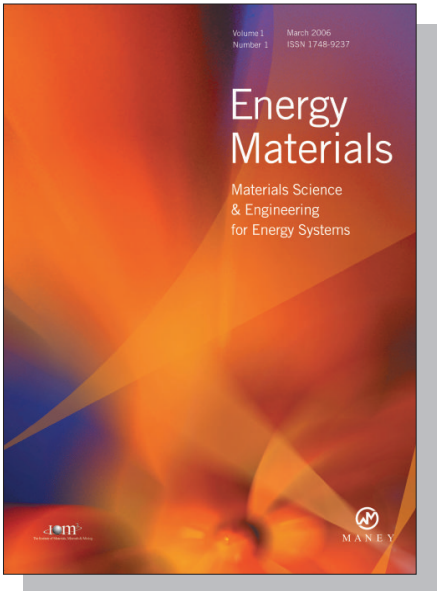

EDITORS

Dr Fujio Abe

NIMS, Japan

Dr John Hald, IPL-MPT, Technical University of Denmark, Denmark

Dr R Viswanathan, EPRI, USA

\section{SUBSCRIPTION INFORMATION}

Volume 1 (2006), 4 issues per year

Print ISSN: 1748-9237 Online ISSN: 1748-9245

Individual rate: $£ 76.00 / U S \$ 141.00$

Institutional rate: $£ 235.00 /$ US $\$ 435.00$

Online-only institutional rate: $£ 199.00 / U S \$ 367.00$

For special $\mathrm{IOM}^{3}$ member rates please email

subscriptions@maney.co.uk

\section{For further information or to subscribe online please visit www.maney.co.uk}



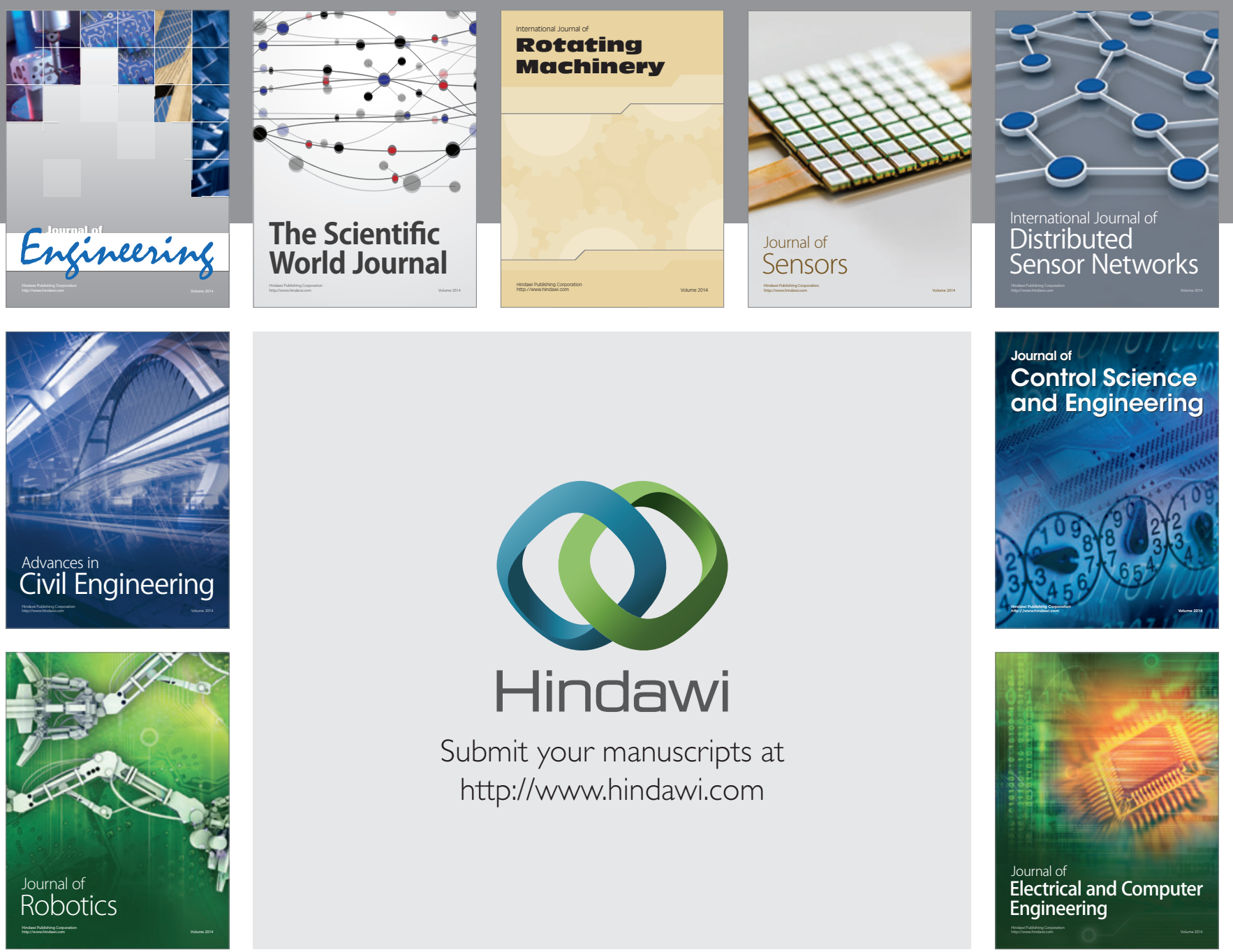

Submit your manuscripts at

http://www.hindawi.com
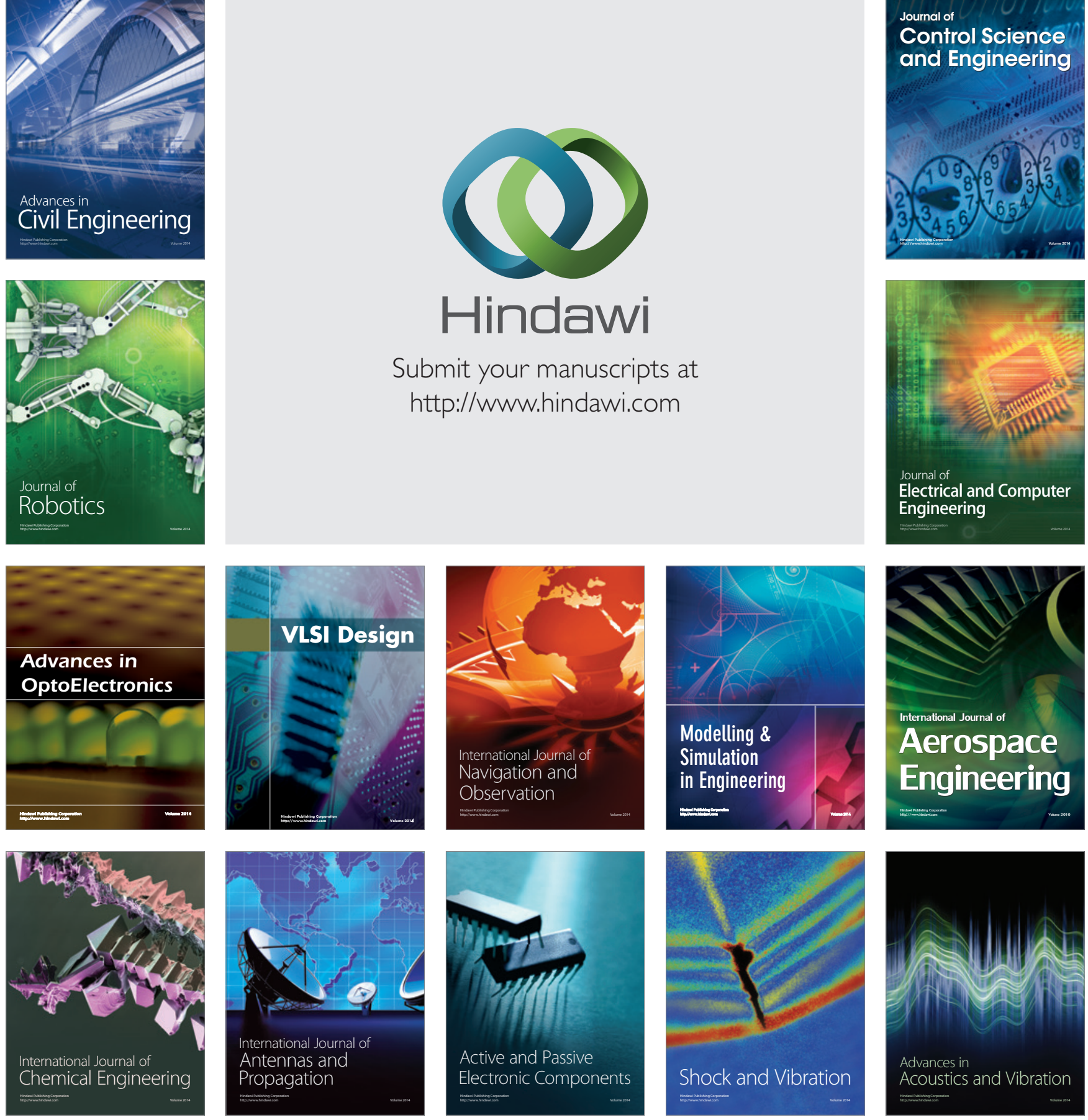